\title{
Erratum to: Comparison of a colonic J-pouch and transverse coloplasty pouch in patients with rectal cancer after an ultralow anterior resection using fecoflowmetric profiles
}

\author{
Yasuo Kobayashi • Minoru Yagi • Tsuneo Iiai • \\ Tatsuo Tani $\cdot$ Satoshi Maruyama • \\ Katsuyoshi Hatakeyama
}

Published online: 10 November 2009

(C) Springer-Verlag 2009

Erratum to: Int J Colorectal Dis (2009) 24:1321-1326

DOI 10.1007/s00384-009-0763-6

The names of the authors were listed incorrectly. The surnames and first names were interchanged. The correct details are shown above.

The online version of the original article can be found at http://dx.doi. org/10.1007/s00384-009-0763-6.

Y. Kobayashi $(\bowtie) \cdot$ T. Iiai · T. Tani · S. Maruyama •

K. Hatakeyama

Department of Gastrointestinal Surgery,

Graduate School of Medical and Dental Sciences,

Niigata University,

1-757 Asahimachi-dori, Chyuo-ku,

Niigata, Niigata 951-8510, Japan

e-mail: kobayasu@med.niigata-u.ac.jp

M. Yagi

Department of Pediatric Surgery, School of Medicine,

Kurume University,

67 Asahimachi,

Kurume, 830-0011 Fukuoka, Japan 